\title{
Comparative Vegetative Growth Responses of Two Peach Cultivars Grown on Size-controlling versus Standard Rootstocks
}

\author{
Antonio Weibel \\ EEA Junín INTA, CC 78 San Martín (5570), Mendoza, Argentina \\ R. Scott Johnson and Theodore M. DeJong 1 \\ Department of Pomology, University of California, One Shields Avenue, Davis, CA, 95616
}

AdDitional INDEX wORds. Prunus persica, dwarfing rootstocks, shoot growth

Abstract. Vegetative growth of two peach (Prunus persica L. Batsch) cultivars Flavorcrest and Loadel growing on six different rootstocks ('Nemaguard', 'Hiawatha', K-146-43, K-146-44, P-30-135, and K-119-50) was analyzed during the third season of growth in an experimental orchard at the University of California Kearney Agricultural Center near Parlier, California. Seasonal trunk cross-sectional area, shoot and internode growth, diurnal stem extension growth rate and summer and dormant pruning weights were measured to determine extent of size-control imparted by the experimental rootstocks compared to the trees on the 'Nemaguard' control and to characterize the nature of the sizecontrolling response. Trunk cross-sectional area growth of trees on the two smallest rootstocks (K-146-43 and K-146-44) was only $25 \%$ to $37 \%$ of the growth of trees on 'Nemaguard', while trees on the other three rootstocks provided an intermediate level of size control. Generally, the seasonal patterns of shoot growth did not vary substantially among trees on the different rootstocks, but average shoot and internode lengths did correspond with tree size. Vigorous watersprout growth was decreased by more than $80 \%$ in the trees on the least vigorous rootstocks compared to trees on 'Nemaguard' resulting in major reductions in the extent of summer and winter pruning weights. Variations in vegetative shoot growth appeared to correspond to variations in daily shoot extension growth rates but more research is needed to explore these relationships.

Agrafted fruit tree is a combination of two different genotypes, the scion and the rootstock. The interaction between the two genotypes is very complex. The transported nutrients and other compounds crossing the bud union influence the scion and rootstock and produce changes that affect tree size, fertility, longevity, pathogen resistance, fruit quality, yield, etc. During the past few decades, apple researchers and fruit growers introduced spur scion varieties and dwarfing rootstocks to control tree size and reduce hand labor costs (Webster, 2001). The increasing density of the orchard plantings to obtain high yields and the accompanying high costs of the hand operations emphasized the necessity of size-controlling rootstocks (DeJong et al., 1999). Unlike apples, there are no widely acceptable size-controlling rootstocks for peaches. The need for such rootstocks to improve the management efficiency of high-density peach orchards induced the University of California Pomology Department to develop a rootstock evaluation program from 1986 to 1994 (DeJong et al., 1997). In this project, rootstocks were selected on the basis of rooting capacity, size controlling performance and compatibility with peach. The resulting selections were the basis of the present study.

There are several theories about the dwarfing mechanisms of size controlling rootstocks (Crabbé, 1984; Lockard et al., 1982; Rom and Carlson, 1987), but none of these theories has been definitively proven. Theories on the dwarfing effect have come from various research approaches, and hormones appear to be related to the dwarfing mechanism in some way (Crabbé, 1984; Kamboj et al., 1997; Richards et al., 1986). Other theories involve bark tissues, which could be the key for explaining the dwarfing mechanism in apples (Lockard et al., 1982; McKenzie, 1961; Simons and Chu, 1984). The graft union, especially the

Received for publication 28 May 2002. Accepted for publication 1 Apr. 2003. ${ }^{1}$ Corresponding author. region near the scion, may reduce the amount of water, growth regulators and nutrients transported to the scion, and has also been suggested to cause a reduction in size or vigor (Childers, 1983; Glenn and Scorza, 1992; Jones, 1984; Soumelidout et al., 1994; Ussahatanonta and Simons, 1988; Zimmermann, 1983). Olien and Lakso (1984) studied water relations of 'Empire' apple on five rootstocks and suggested that differences in mean midday stem potential were due to high resistances to flow at the graft union or to high root hydraulic resistance.

Rootstocks can markedly affect the vegetative growth of the scions. However, the vegetative growth can be defined by several parameters. Trunk cross-sectional area, number of terminal and lateral shoots, total shoot length, and internode length, are the most conspicuous. Trunk cross-sectional area (TCA) is correlated to total above-ground mass of apple trees (Forshey and Elfving, 1989; Heinicke, 1922; Khatamian and Hilton, 1977; Murray, 1927; Tustin et al., 1997; Westwood and Roberts, 1970) and it is commonly used to compare differences in growth among fruit trees on different rootstocks. Shoot growth has a large influence on the fruitfulness of trees and the amount of vegetative growth removed in summer and dormant pruning (Childers, 1973; Westwood, 1978). In addition, rootstocks can also affect the seasonal pattern and time of cessation of shoot growth (Barlow, 1964; Forshey and Elfving, 1989; Maggs, 1957; Preston, 1958, 1968; 1957; Swarbrick, 1929; Vyvyan, 1935). There have been relatively few studies on seasonal vegetative growth patterns of peach scion varieties (DeJong et al., 1987) and fewer related to peach rootstock effects. Internode length may also be affected by dwarfing rootstocks. Peach trees grafted on dwarfing rootstocks had shorter internodes compared to trees on the more vigorous rootstocks (Murase et al., 1990). In addition, dwarfing apple rootstocks appear to have wider crotch angles with the uprightgrowing ‘Delicious' variety (Warner,1991). 
Seasonal growth is the integrated result of diurnal growth over many days. Diurnal changes in plant water status have been described for many species, including peach trees (Berman and DeJong, 1996, 1997a, 1997b; Chalmers and Wilson 1978; Larson et al., 1988; Simmoneau et al., 1993a, 1993b). Berman and DeJong (1997b) modeled peach stem growth rate showing that the diurnal rate of change of stem water potential markedly influenced the extension growth of peach stems. Water relations studies of 'Empire' apple on five different rootstocks (Olien and Lakso, 1984) indicated that stem water potential of the most dwarfing rootstocks were lower than the more vigorous rootstocks. Differences in water potential, especially at midday, could be produced by high hydraulic resistance at the graft union or root level, and may partially explain the mechanism for the reduction in the diurnal extension shoot growth rate, though this has not been clearly documented.

This study was undertaken to describe the primary vegetative parameters influenced by size-controlling rootstocks being tested for peach. Seasonal and diurnal shoot and TCA growth were studied on two peach varieties grafted onto rootstocks ranging in vigor. Reduced seasonal and diurnal growth was expected on the more size-controlling rootstocks. In addition, we attempted to determine if the period of shoot extension growth was shorter for semi-dwarfing rootstocks. Total seasonal shoot growth was studied on primary, secondary and tertiary shoots to determine whether growth patterns differed among rootstocks.

\section{Materials and Methods}

Data were obtained in 1998 and 1999 on two peach [Prunus persica (L.) Batsch] cultivars, 'Flavorcrest' (an early fresh market, freestone cultivar) and 'Loadel' (an early clingstone, processing cultivar) grafted on six different rootstocks: 'Nemaguard' $(P$. persica seedling, the standard vigorous rootstock for California), 'Hiawatha' (open-pollinated seedling of a P. besseyi Bailey x $P$. salicina Lindl. hybrid), K-146-43, K-146-44, P-30-135 [P. salicina Lindl. $\mathrm{X}$ P. persica (L.) Batsch hybrids] and K-119-50 $[P$. salicina Lindl. $\mathrm{x}$ P. dulcis (Mill.) D.A. Webb hybrid]. Trees were planted at Kearney Agricultural Center of the University of Califorina, Parlier, Calif. in 1996. Trees were trained to the standard open vase system and spaced in relation to the anticipated size of rootstock/scion combination. Densities were 420 , 480 and 560 trees/ha for 'Nemaguard' and P-30-135, K-119-50 and 'Hiawatha', and K-146-44 and K-146-43 trees, respectively. Trees were planted in a randomized complete block design with four replications and four trees per replicate. The plot was managed according to normal commercial practices with a herbicide strip in the tree row and a mowed cover crop strip between rows. Trees were flood irrigated to replace $100 \%$ of estimated evapotranspiration. Seasonal temperature was recorded at a California Irrigation Management Information System (CIMIS) station located within $1 \mathrm{~km}$ of the plot. Vegetative growth was monitored by measuring trunk cross-sectional area (TCA), shoot and internode length, summer and winter pruning weights, and diurnal extension growth.

TrunK CROSS-SECTIONAL AREA AND SHOOT AND INTERNODE GROWTH. Initial and final trunk diameters at $20 \mathrm{~cm}$ from the soil were measured on all treatment trees at the beginning and after the end of the 1998 growing season. Trunk cross-sectional area (TCA) was subsequently calculated assuming a circular trunk. Seasonal increment in TCA was followed on one tree per treatment replication (the tree closest to the mean size) at intervals of 20 to
$30 \mathrm{~d}$ during the growing season. Daily growth rate and percent of total annual TCA increment were calculated to compare the cycle of trunk growth among different rootstocks.

Shoot length growth during the season was measured on two scaffolds in the same trees of each rootstock replicate that were selected for measurement of seasonal growth of the TCA in both varieties. Three different types of shoots were selected and tagged: shoots arising directly from the scaffold (S), shoots arising near the base of previous-year hanger shoots (B) and terminal shoots growing from the same hangers (T). Hangers are defined as unbranched 1-year-old shoots from the previous season that were selected for fruit bearing during dormant pruning. Shoot growth was recorded every 20 to $30 \mathrm{~d}$ from May to October.

In January 1999, the number of nodes were counted on each of the tagged shoots in the 'Loadel' trees. Mean length of each type of shoot from the two scaffolds was also measured. Mean internode length was calculated for trees on each rootstock based on node number and shoot length data. One medium-sized scaffold was tagged from each of the selected trees, and the number and length of 1-year-old shoots, new lateral shoots and watersprout shoots were recorded. Angles of insertion of shoots that came directly from the scaffold were also measured. All scaffold diameters of these trees were also measured at the base of the scaffolds at the beginning and the end of the growing season in 1998 to establish the yearly increase of the scaffold cross-sectional area (SCA). The number of shoots and laterals per tree were calculated for each rootstock based on data from the one scaffold and its SCA compared to the total SCA of the whole tree. The length of primary growth originating from dormant buds from the previous season was calculated for each tree. Secondary and tertiary growth generated from buds formed during the current season was also estimated. By adding these three kinds of growth, the total shoot growth was calculated per tree considering the total primary, secondary and tertiary shoot length growth per measured scaffold and the total SCA of the tree. Shoot growth data from the measured scaffold was multiplied by the ratio: total SCA/individual SCA. Additionally, the ratio between the different measured parameters and the increment in the scaffold cross-sectional area (SCA) was calculated.

The current-year shoots with lateral shoots and basal diameters $>7.5 \mathrm{~mm}$ were considered to be watersprouts and their diameters, number of laterals, primary, secondary, tertiary and total length growth were recorded separately. Number of watersprouts and laterals, and length of watersprout growth per tree were calculated by the same procedure used for shoots. Relationships between shoot length and increase of SCA were compared among rootstocks.

DiURnAl STEM EXTENSION GROWTH RATE. Diurnal stem extension rate (SER) was measured on well exposed vigorous shoots on 'Loadel' open vase trees. SER was measured by making fine ink marks with a permanent marker on selected stems on 22 to 23 June 1999. The distance between fine marks was measured at $\approx 4$-h intervals during the day and 6-h intervals in the night with a digital caliper. SER was determined by dividing the length increment (amount of change in distance between marks) by the amount of time between measurements (Berman and DeJong, 1997b). SER was studied on two kind of shoots: Terminal shoots on hangers at $\approx 1.5 \mathrm{~m}$ from the soil surface and vigorous upright watersprouts in the upper part $(\approx 3 \mathrm{~m})$ of the trees. The largest shoots (watersprouts) in each of the trees per replicate (two trees per replication) were used. For the terminal shoots, one growing shoot per tree and replicate was selected. Stem water potential $\left(\psi_{\mathrm{ST}}\right)$ was measured on mature leaves, close to the scaffolds. Leaves 
Table 1. Mean annual TCA increment of 3-year-old 'Loadel' and 'Flavorcrest' open vase trees grafted on six different rootstocks.

\begin{tabular}{|c|c|c|c|c|}
\hline \multirow[b]{2}{*}{ Rootstock } & \multicolumn{2}{|c|}{ Loadel } & \multicolumn{2}{|c|}{ Flavorcrest } \\
\hline & $\begin{array}{l}\text { Initial TCA } \\
\left(\mathrm{cm}^{2}\right)\end{array}$ & $\begin{array}{l}\text { Yearly TCA increment } \\
\left(\mathrm{cm}^{2}\right)\end{array}$ & $\begin{array}{l}\text { Initial TCA } \\
\quad\left(\mathrm{cm}^{2}\right)\end{array}$ & $\begin{array}{l}\text { Yearly TCA increment } \\
\qquad\left(\mathrm{cm}^{2}\right)\end{array}$ \\
\hline K-146-44 & $18.6(1.91) \mathrm{c}^{\mathrm{z}}$ & $14.7(2.22) \mathrm{c}$ & $24.3(0.89) \mathrm{c}$ & $27.4(0.77) \mathrm{b}$ \\
\hline K-146-43 & $25.6(2.03) \mathrm{c}$ & $17.6(1.81) \mathrm{c}$ & $28.4(2.24) \mathrm{c}$ & $29.0(2.01) b$ \\
\hline Hiawatha & $54.6(3.35) \mathrm{b}$ & $37.2(2.44) \mathrm{b}$ & $52.4(5.97) \mathrm{b}$ & $47.7(4.40) \mathrm{c}$ \\
\hline P-30-135 & $59.6(2.69) \mathrm{b}$ & $37.5(1.93) \mathrm{b}$ & $57.6(2.31) b$ & 70.0 (1.94) a \\
\hline K-119-50 & $56.3(1.77) \mathrm{b}$ & $36.9(2.00) \mathrm{b}$ & $51.8(6.05) \mathrm{b}$ & $54.0(2.52) \mathrm{b}$ \\
\hline Nemaguard & $74.0(2.66) \mathrm{a}$ & $57.2(2.05) \mathrm{a}$ & $77.4(2.14) \mathrm{a}$ & $75.0(2.83) \mathrm{a}$ \\
\hline
\end{tabular}

z Different letters within columns indicate that means differ significantly (Tukey $P<0.05$ ). Numbers in parenthesis are SE.

were covered with aluminum covered plastic bags (McCutchan and Shackel, 1992) at least $1 \mathrm{~h}$ before the measurements. After this period, it was assumed the leaf $\psi_{\mathrm{w}}$ was equilibrated with that of the xylem sap to which the leaf was attached. Then, the leaves were cut and put in the pressure chamber (model 3005 , Soil Moisture Equipment Corporation, Santa Barbara, Calif. Two leaves per tree were used to measure stem water potential.

INFLUENCE OF ROOTSTOCKS ON PRUNING WEIGHTS. All trees except the ones chosen for the previously described seasonal shoot growth measurements were summer pruned on $18 \mathrm{Aug}$. 1998. Summer pruning consisted of removing only water sprouts and competitive, vigorous shoots on the main scaffolds. Fresh weight of the harvested material was obtained from individual trees. Stems and leaves from one tree per block were dried at $65{ }^{\circ} \mathrm{C}$ to convert fresh weight to dry weight. All trees were also dormant pruned in January 1999. Samples of fresh weight from each rootstock/scion combination were dried at $65^{\circ} \mathrm{C}$ to convert fresh weight to dry weight. Dormant pruning consisted of removing vigorous shoots and shaded limbs. Strong, upright fruiting shoots were headed and the remaining shoots were thinned as required for the next season's fruit production.

Fruit Yield MEASUREMENTS. Standard yield studies were done on 'Loadel' and 'Flavorcrest' trees on the various rootstocks. All trees were normally (commercially) thinned. Fruits were harvested following standard commercial procedures. In 'Loadel' trees, harvest was done in five picks $(6,10,15,21$, and 28 July 1998) while 'Flavorcrest' was harvested in three parts (19, 23, and 30 June 1998). Number of fruits per tree and total fruit weight per tree were recorded. Means were compared using Tukey test $(P=0.05)$.

SAS software (SAS Institute, Cary, N.C.) was used for analyses of variance to test for differences among treatments. Multiple mean separations were carried out using Tukey's multiple range tests $(P<0.05)$.

\section{Results}

TRUNK CROSS-SECTIONAL AREA MEASUREMENTS. The initial TCA and yearly increment were comparable in 'Loadel' and 'Flavorcrest' trees. Trees on K-146-44 and K-146-43 had the smallest increment in TCA, while trees on 'Nemaguard' had the largest increase with both cultivars (Table 1). During the growing season, K-146-44

and K-146-43 had a clear negative effect on the TCA growth rate relative to the other rootstocks (Fig. 1). Trees on 'Nemaguard' had the largest relative increase of TCA. Trees on 'Nemaguard', the most vigorous rootstock, had the highest percentage increase in TCA during the first and middle part of season. Trees grafted on P-30-135 and K-119-50 grew at an intermediate rate during the whole vegetative growing period (Fig. 1).

SEASONAL SHOOT GROWTH PATTERN. In general, basal shoots (B) on 1-year-old fruiting shoots (hangers) reached close to their final length early in the season but 'Loadel' shoots on 'Nemaguard' kept growing later into the season compared to the other rootstocks (Fig. 2A). Shoots on 'Loadel' trees on K-146-44 grew early, slowed down and then resumed growth toward the end of the season (Fig. 2A). Shoots on 'Flavorcrest' trees on 'Hiawatha' grew later in the season than the rest of the rootstocks. Shoots on trees grafted on the two most dwarfing rootstocks, K-146-44 and K-146-43 grew mostly at the beginning of the season (Fig. 2B).

New shoots arising directly from the scaffold branches $(\mathrm{S})$ in 'Loadel' trees on 'Nemaguard' grew more rapidly than the other rootstocks, especially at the beginning of the vegetative

Fig. 1. The seasonal pattern of trunk cross-sectional area (TCA) growth of 'Loadel' (A) and 'Flavorcrest' (B) and of TCA growth rate of 'Loadel (C) and 'Flavorcrest' (D) third leaf open vase peach trees growing on six different rootstocks. Error bars represent \pm 1 standard error of the mean.
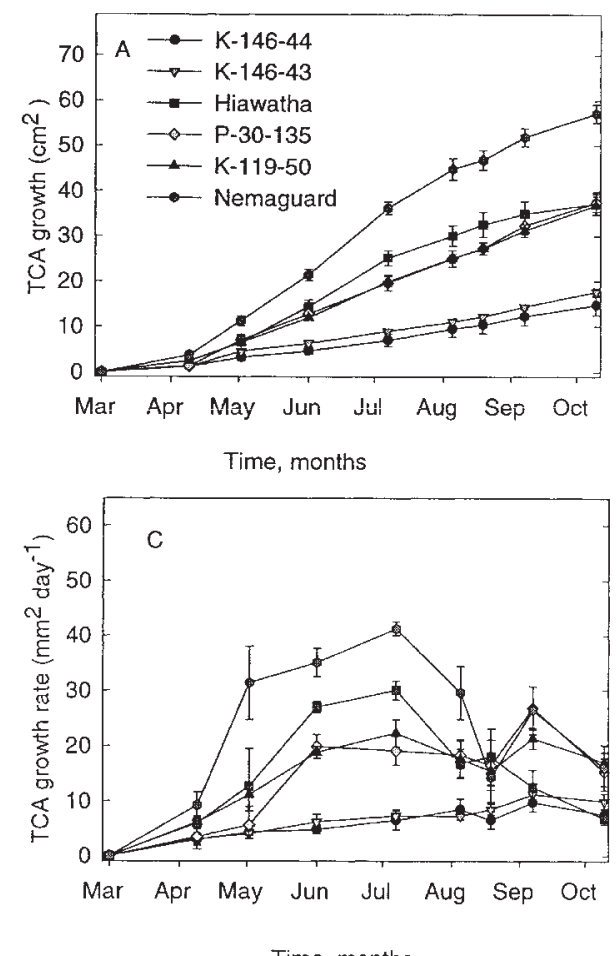

Time, months
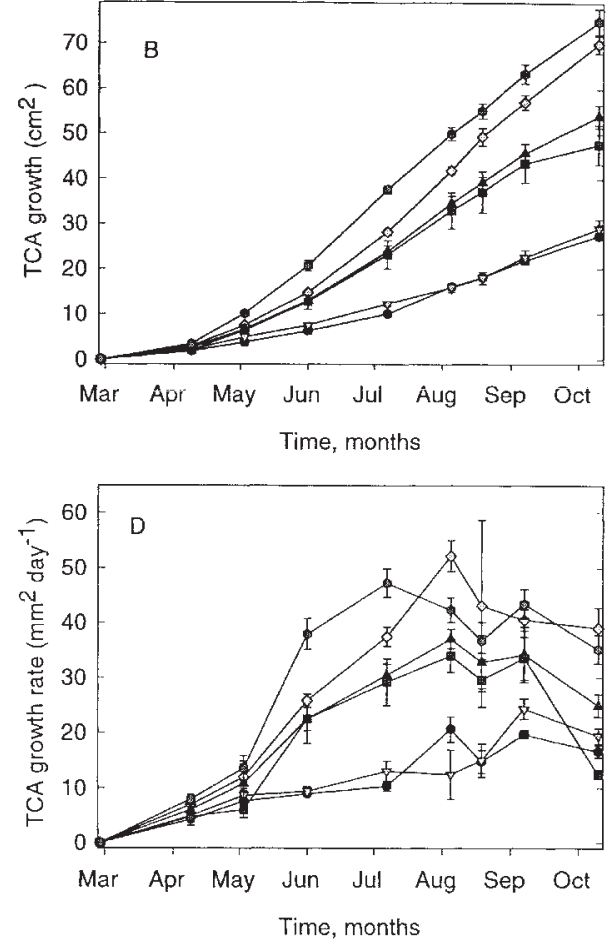

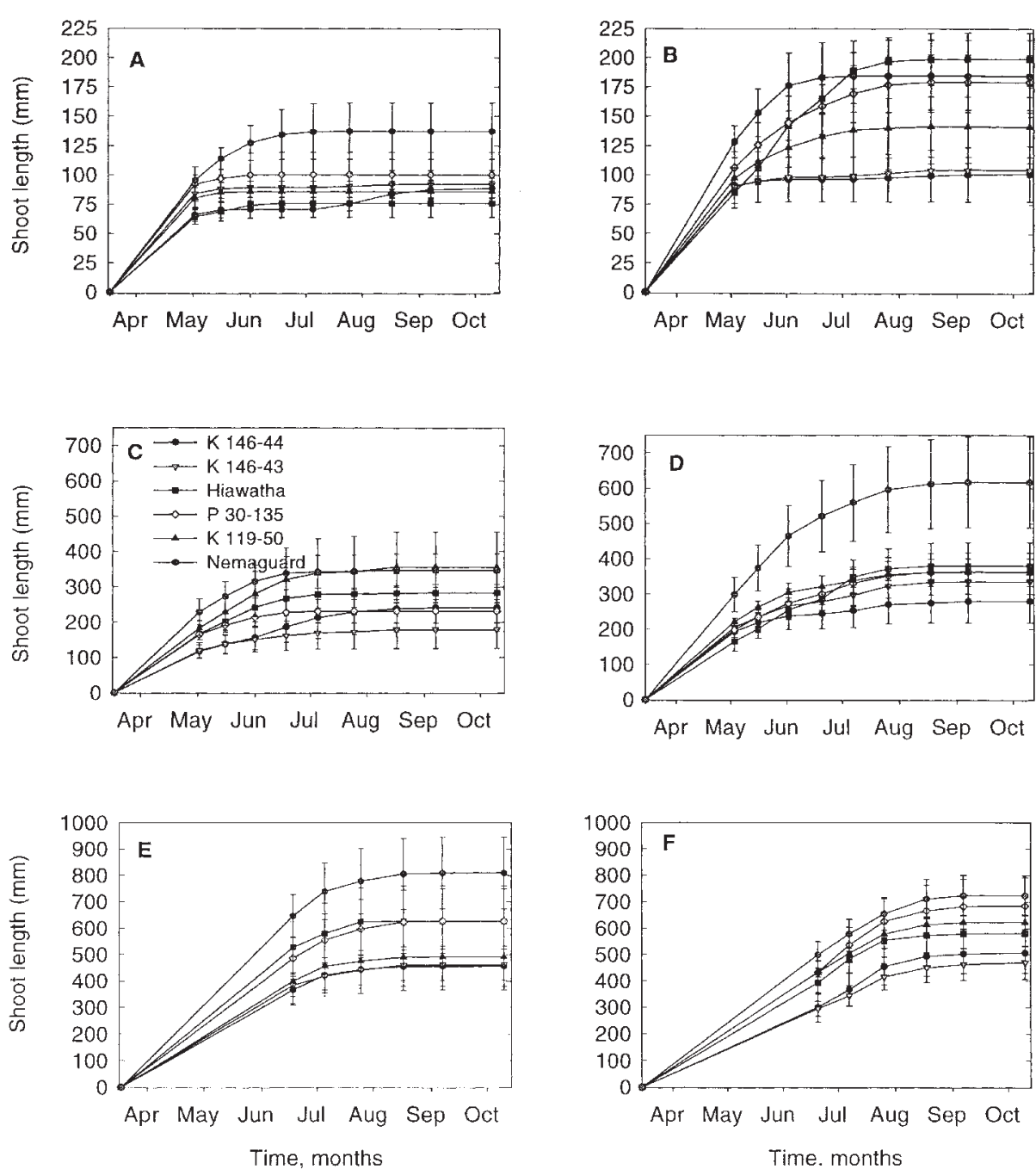

Fig. 2. The seasonal pattern of average length of basal stems (B) arising from 1-year-old wood (A and B), shoots (S) arising directly from scaffolds (C and D), and terminal shoots ( $T$ ) arising from 1-year-old wood ( $\mathbf{E}$ and $\mathbf{F}$ ) in 'Loadel' $(\mathbf{A}, \mathbf{C}$, and $\mathbf{E})$ and 'Flavorcrest' $(\mathbf{B}, \mathbf{D}$, and $\mathbf{F})$ open vase peach trees on six different rootstocks. Error bars represent \pm 1 standard error of the mean.

season (Fig. 2C). 'Nemaguard' stimulated 'Flavorcrest' S shoot growth more than 'Loadel'. 'Flavorcrest' trees on K-146-44 and K146-43 had significantly reduced $S$ shoot stem length relative to 'Nemaguard' (Fig. 2D).

Terminal shoots on fruiting hangers growing from terminal buds $(\mathrm{T})$ on 'Loadel' and 'Flavorcrest' trees continued growing almost to the end of the vegetative period. On 'Nemaguard', the 'Loadel' shoots initially grew rapidly and this initial growth was related to the final length. The most size controlling rootstocks, K-146-44 and K-146-43, produced trees with the shortest shoots during the vegetative period and consequently at the end of the year (Fig. 2E). No statistically significant differences were found among rootstocks for growth of T shoots with 'Flavorcrest', although the measurement means had the same general seasonal pattern as 'Loadel' (Fig. 2F).

DiURNAL STEM EXTENSION GROWTH. On 22-23 June 1999, diurnal growth was measured on two kinds of shoots; terminal shoots and watersprouts. Growth of terminal shoots did not statistically differ, however the mean general trend of terminal shoot growth of trees on 'Nemaguard' was slightly higher than trees on K146-43, especially at midday and early afternoon (Fig. 3B). Stem water potential of trees on 'Nemaguard' was generally less negative than trees on K-146-43 (Fig. 3C). Diurnal watersprout shoot growth followed a similar trend as terminal shoots although the absolute growth values of watersprouts were higher (Fig. 3B). Trees on K-146-43 tended to have the least growth during the period when stem water potential was recovering and temperature was decreasing. (Fig. 3C).

SHOOT GROWTH PER TREE. 'Loadel' trees on 'Nemaguard' had the highest number of 1-year-old shoots per tree and were statistically different from K-146-44, which had the lowest number of shoots per tree. Trees on 'Nemaguard' and K-119-50 had the most laterals per tree, while trees on $\mathrm{K}$ 146-44 and K-146-43 had about one-sixth the number of laterals per tree compared to 'Nemaguard' (Table 2). Trees grafted on 'Nemaguard' produced about three times more primary growth per tree than trees on the most dwarfing rootstock, K-14644. Growth generated by lateral shoots (secondary and tertiary growth) showed clear differences among rootstocks. Secondary and tertiary growth in trees on $\mathrm{K}$ 146-44 was less than one-sixth of trees on 'Nemaguard'(Table 2). Total length growth (primary, secondary and tertiary growth) per tree was markedly influenced by rootstocks and followed the same pattern as TCA increment. Growth on 'Nemaguard' was substantially greater than on all the other rootstocks while growth on K-146-44 and K-146-43 was the least. The amount of 1-year-old wood in trees on K-146-44 and K-146-43 was about one-third that of trees on 'Nemaguard' (Table 2). Between $4.6 \%$ and $6.6 \%$ of the total estimated numbers of shoots per tree (Table 2 ) were watersprouts with a basal diameter $>7.5 \mathrm{~mm}$. There was a clear trend toward increasing water sprout growth per tree with the more vigorous rootstocks (Fig. 4A) but when expressed on a scaffold cross-sectional area basis, only the smallest rootstocks appeared to differ from 'Nemaguard' (Fig. 4B). On a shoot length basis, watersprout growth of trees on P-30-135, K-11950, 'Hiawatha' and 'Nemaguard' represented $48 \%-53 \%$ of the total annual extension growth. In contrast, watersprout growth only represented $26 \%$ to $32 \%$ of the total extension growth per tree for trees on K-146-44 and K-146-43.

INSERTION ANGLE OF SHOOTS ARISING FROM SCAFFOLDS. The angle between the insertion of 1-year-old shoots and scaffolds from which they originated appeared not to be influenced by the rootstocks. Similar values for all the rootstocks were recorded at the end of the season. The mean angle of insertion varied between 50.4 and $54.9^{\circ}$ relative to the scaffold across trees on the various rootstocks.

NUMBER OF NODES AND INTERNODE LENGTH OF 1-YEAR-OLD SHOOTS. Shoots were measured at the end of the season to determine shoot and internode length in 'Loadel'. The mean internode length of the shortest tagged shoots (basal shoots from hangers, B), differed among rootstock (Table 3). Although mean internode lengths only differed significantly between 'Nemaguard' (the longest) and 'Hiawatha' (the shortest), the general pattern 


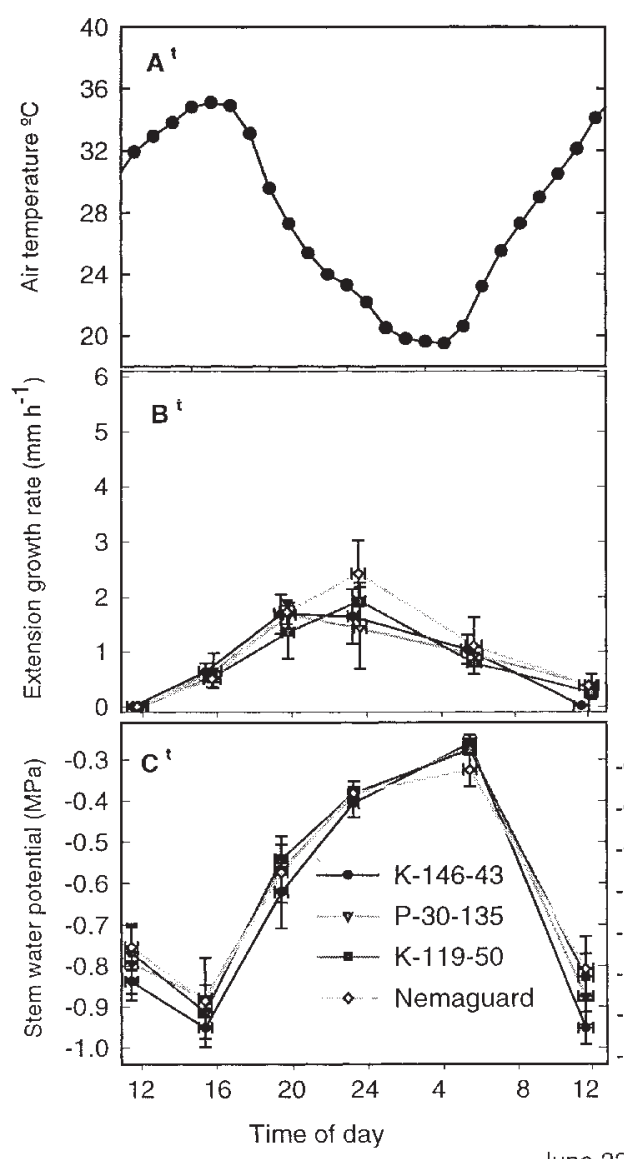

June 22-23, 1999

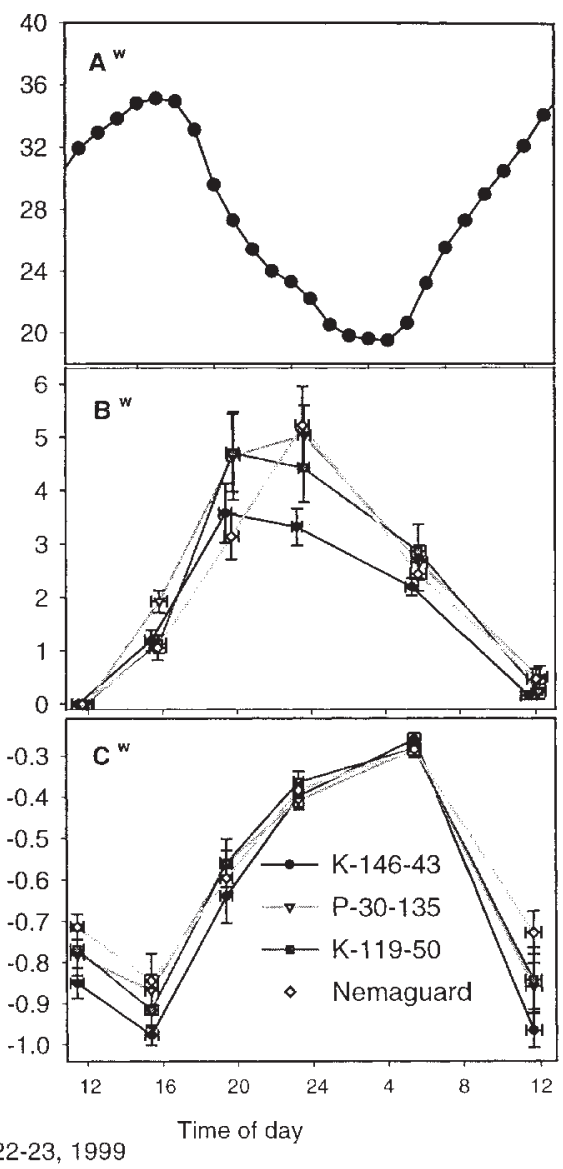

Fi.g 3. Rootstock influence on the diurnal extension growth rate of terminal shoots (t) and watersprouts (w) of 'Loadel' open vase peach trees for 22 to 23 June 1999. (A) Average air temperature, (B) hourly stem extension rate, and (C) diurnal pattern of stem water potential. Vertical bars represent \pm 1 standard error of the measurement means and horizontal bars indicate standard error from the mean time of measurement.

among all branch types indicated that internode length was the longest on shoots that grew on trees grafted on 'Nemaguard'. The number of nodes was similar in the different rootstocks, so most of the variation in shoot length was attributable to internode length (Table 3). In the shoots from scaffolds (S), mean internode lengths were largest on trees on 'Nemaguard' and K-119-50, and they were statistically different from trees on $\mathrm{K}-146-44$ and K-146-43. Trees on P-30-135 and 'Hiawatha' had intermediate internode lengths. Trees grafted on 'Nemaguard' and $\mathrm{K}-119-50$ had the longest shoots, however there were no significant differences in the number of nodes among trees on the different rootstocks, so again most of the variation was due to mean internode length (Table 3). The longest shoots, T shoots, had the shortest mean internode lengths on trees on K-146-44 and K-146-43. Trees on 'Nemaguard' produced the longest $\mathrm{T}$ shoots and the differences in length were primarily related to differences in internode length rater than number of nodes. (Table 3).

Pruning weights. In 'Loadel' trees, dry and fresh weight per tree of leaves and stems from summer pruning was highest in trees on 'Nemaguard', followed by trees on K-119-50 and P-30-135. Trees on K-146-44 and K-14343 needed just a light pruning (Table 4 ). With 'Flavorcrest', rootstocks could be separated into three groups on the basis of dry and fresh weight obtained from the summer pruning in August. The greatest vegetative material was taken from trees on 'Nemaguard', and the least from K-146-44 and K-146-43 trees. Trees on K-119-50, P-30-135, and 'Hiawatha' were intermediate (Table 4).

Rootstocks also markedly influenced fresh and dry mass removed during dormant pruning. 'Loadel' trees required less dormant pruning than 'Flavorcrest' trees. Fresh and dry weights of prunings per tree were greatest for trees on 'Nemaguard' and the least for K-146-44. Prunings from trees on P-30-135 and K-119-50 had greater dry and fresh weights than prunings from trees on 'Hiawatha', K-146-44 and K-146-43 (Table 4). 'Flavorcrest' trees on 'Nemaguard' required significantly more pruning than the other rootstocks. In contrast, trees on K-146-44 and K-146-43 had the least dormant prunings. (Table 4).

Crop YiELDS. Loadel trees on 'Nemaguard' rootstocks had the largest mean fresh fruit yield per tree. Similarly, 'Flavorcrest' trees on 'Nemaguard' also had greater yield per tree than trees on all

Table 2. Calculated mean number of 1-year old shoots, new lateral shoots and growth in length per tree in 'Loadel' open vase trees, on six different rootstocks.

\begin{tabular}{|c|c|c|c|c|c|}
\hline \multirow[b]{2}{*}{ Rootstocks } & \multirow[b]{2}{*}{$\begin{array}{c}\text { No. of } \\
\text { 1-year-old } \\
\text { shoots/treez,y }\end{array}$} & \multirow[b]{2}{*}{$\begin{array}{c}\text { No. of } \\
\text { new lateral } \\
\text { shoots/tree }\end{array}$} & \multicolumn{3}{|c|}{ Shoot length/tree } \\
\hline & & & $\begin{array}{l}\text { Primary } \\
\text { growth/ } \\
\text { tree }(\mathrm{m})^{\mathrm{w}}\end{array}$ & $\begin{array}{l}\text { Secondary and } \\
\text { tertiary growth/ } \\
\text { tree }(\mathrm{m})^{\mathrm{v}}\end{array}$ & $\begin{array}{l}\text { Total } \\
\text { growth/ } \\
\text { tree }(\mathrm{m})^{\mathrm{u}}\end{array}$ \\
\hline$\overline{\mathrm{K}-146-44}$ & $628.0(88.1) b$ & $142.0(34.6) \mathrm{b}$ & $122.39(19.75) \mathrm{d}$ & $37.46(9.85) \mathrm{c}$ & $159.85(23.94) \mathrm{c}$ \\
\hline K-146-43 & 809.0 (125) ab & $202.3(47.1) b$ & $152.31(8.29) \mathrm{cd}$ & $51.22(15.69) \mathrm{bc}$ & $203.53(14.48) \mathrm{c}$ \\
\hline Hiawatha & 985.5 (107) ab & $603.3(58.1) \mathrm{ab}$ & $238.73(19.74) b$ & $177.11(22.02) \mathrm{a}$ & $415.83(24.18) b$ \\
\hline P-30-135 & 922.4 (117) ab & $429.7(60.4) a b$ & 215.48 (18.39) bc & $155.73(22.75) a b$ & $354.99(35.83) \mathrm{b}$ \\
\hline K-119-50 & $1,022.1(108) a b$ & $599.7(88.3)$ a & $247.41(17.63) \mathrm{b}$ & $184.66(22.20) \mathrm{a}$ & $432.07(33.67) \mathrm{b}$ \\
\hline Nemaguard & $1,266.4(78.5)$ a & $888.7(253) \mathrm{a}$ & $366.08(24.12) \mathrm{a}$ & $231.42(38.72) \mathrm{a}$ & $597.50(60.89) \mathrm{a}$ \\
\hline
\end{tabular}

${ }^{z}$ Different letters within columns indicate that means differ significantly (Tukey $P<0.05$ ). Numbers in parenthesis are SE.

yone-year-old shoots.

x Total number of laterals includes laterals of second- and third-order growth.

" Growth originated by a dormant bud.

${ }^{v}$ Growth originated from lateral and sublateral buds during the vegetative growth period.

u Primary, secondary and tertiary growth added. 
the other rootstocks but less than the 'Loadel' trees (Table 5). The differences in crop yield between trees on the various rootstocks
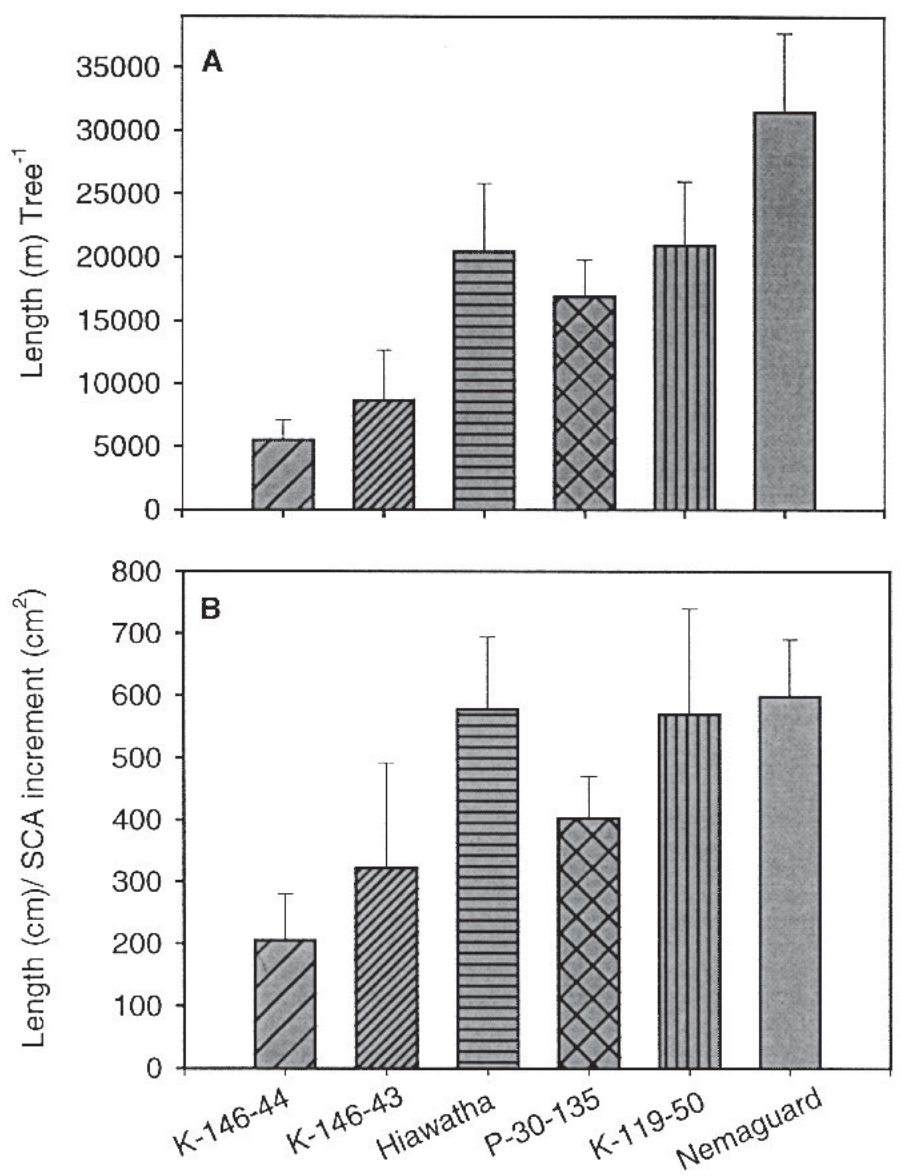

\section{Rootstocks}

Fig. 4. Total length of watersprouts expressed as shoot length (including latera shoot lengths) per tree (A) and per unit of annual increase of scaffold crosssectional area (B) in 'Loadel' open vase peach trees on six different rootstocks. Bars indicate \pm 1 standard error of the mean. corresponded fairly well to differences in tree size with both the 'Loadel' and 'Flavorcrest' trees on the two most size-controlling rootstocks (K-146-43 and K-146-44) carrying the least numbers of fruit and producing the lowest yields (Table 5). The mean fruit size on the smaller rootstocks also tended to be less than for trees on the more vigorous rootstocks (data not shown).

Table 3. Average shoot length, number of nodes per stem and internode length of basal shoots arising from 1-year-old wood (hangers), shoots arising directly from the scaffold and terminal shoots arising from hangers, in 'Loadel' open vase trees growing on six rootstocks (means and standard errors).

\begin{tabular}{cccc}
\hline Rootstocks & $\begin{array}{c}\text { Shoot length } \\
(\mathrm{mm})\end{array}$ & $\begin{array}{c}\text { No. of nodes/ } \\
\text { shoot }\end{array}$ & $\begin{array}{c}\text { Internode length } \\
(\mathrm{mm})\end{array}$ \\
\hline Basal shoots from hangers & & \\
K-146-44 & $89.0(8.80) \mathrm{b}$ & $10.32(1.07) \mathrm{a}$ & $8.18(0.88) \mathrm{ab}$ \\
K-146-43 & $90.2(11.8) \mathrm{ab}$ & $9.55(0.68) \mathrm{a}$ & $9.04(0.29) \mathrm{ab}$ \\
Hiawatha & $76.1(12.2) \mathrm{b}$ & $9.17(0.33) \mathrm{a}$ & $7.75(0.23) \mathrm{b}$ \\
P-30-135 & $100.4(19.2) \mathrm{ab}$ & $9.45(0.54) \mathrm{a}$ & $9.78(0.83) \mathrm{ab}$ \\
K-119-50 & $86.1(8.71) \mathrm{b}$ & $9.19(0.40) \mathrm{a}$ & $8.89(0.89) \mathrm{ab}$ \\
Nemaguard & $137.4(23.8) \mathrm{a}$ & $11.15(0.32) \mathrm{a}$ & $10.66(0.46) \mathrm{a}$ \\
Terminal shoots from hangers & & \\
K-146-44 & $456.8(75.9) \mathrm{c}$ & $29.47(0.67) \mathrm{ab}$ & $14.63(1.04) \mathrm{c}$ \\
K-146-43 & $462.2(58.4) \mathrm{c}$ & $30.10(2.49) \mathrm{ab}$ & $14.87(0.72) \mathrm{c}$ \\
Hiawatha & $627.9(134) \mathrm{b}$ & $33.07(1.27) \mathrm{ab}$ & $17.74(0.79) \mathrm{b}$ \\
P-30-135 & $627.9(121) \mathrm{b}$ & $33.82(1.99) \mathrm{ab}$ & $16.89(0.85) \mathrm{cb}$ \\
K-119-50 & $491.9(125) \mathrm{bc}$ & $27.85(2.64) \mathrm{b}$ & $15.45(1.19) \mathrm{cb}$ \\
Nemaguard & $809.3(135) \mathrm{a}$ & $37.15(1.49) \mathrm{a}$ & $20.97(0.54) \mathrm{a}$ \\
Shoots from scaffold & & & \\
K-146-44 & $241.7(36.1) \mathrm{ab}$ & $18.05(1.14) \mathrm{a}$ & $11.91(1.10) \mathrm{b}$ \\
K-146-43 & $179.5(22.2) \mathrm{b}$ & $13.95(0.86) \mathrm{a}$ & $11.09(0.62) \mathrm{b}$ \\
Hiawatha & $283.0(42.3) \mathrm{ab}$ & $16.52(1.53) \mathrm{a}$ & $14.74(1.01) \mathrm{ab}$ \\
P-30-135 & $231.7(16.2) \mathrm{ab}$ & $14.05(0.61) \mathrm{a}$ & $14.76(0.24) \mathrm{ab}$ \\
K-119-50 & $348.3(56.6) \mathrm{ab}$ & $18.37(2.09) \mathrm{a}$ & $16.01(0.86) \mathrm{a}$ \\
Nemaguard & $346.5(31.3) \mathrm{a}$ & $16.95(0.94) \mathrm{a}$ & $18.48(1.15) \mathrm{a}$ \\
\hline
\end{tabular}

${ }^{2}$ Different letters within columns indicate that means differ significantly (Tukey $P<0.05$ ). Numbers in parenthesis are SE.

Table 4. The mean fresh and dry weight of 'Loadel' and 'Flavorcrest' summer and winter prunings from standard open vase trees, affected by different rootstocks (means and standard errors).

\begin{tabular}{|c|c|c|c|c|}
\hline \multirow[b]{2}{*}{ Rootstock } & \multicolumn{2}{|c|}{ Loadel } & \multicolumn{2}{|c|}{ Flavorcrest } \\
\hline & $\begin{array}{l}\text { Fresh wt } \\
(\mathrm{kg} / \text { tree })\end{array}$ & $\begin{array}{c}\text { Dry wt } \\
(\mathrm{kg} / \text { tree })\end{array}$ & $\begin{array}{l}\text { Fresh wt } \\
(\mathrm{kg} / \text { tree })\end{array}$ & $\begin{array}{c}\text { Dry wt } \\
\text { (kg/tree) }\end{array}$ \\
\hline \multicolumn{5}{|c|}{ Summer pruning weight, 18 Aug. 1998} \\
\hline K-146-44 & $0.33(0.13) \mathrm{d}$ & $0.11(0.04) \mathrm{d}$ & $2.08(0.42) \mathrm{c}$ & $0.94(0.17) \mathrm{c}$ \\
\hline K-146-43 & $1.57(0.29) \mathrm{d}$ & $0.59(0.13) \mathrm{d}$ & $1.84(0.24) \mathrm{c}$ & $0.80(0.06) \mathrm{c}$ \\
\hline Hiawatha & $2.86(0.74) \mathrm{cd}$ & $1.06(0.29) \mathrm{cd}$ & $9.19(0.64) b$ & $3.95(0.61) \mathrm{b}$ \\
\hline P-30-135 & $4.80(0.64) \mathrm{bc}$ & $1.83(0.23) \mathrm{bc}$ & $11.32(1.23) b$ & $4.33(0.40) b$ \\
\hline K-119-50 & $5.76(0.31) b$ & $2.14(0.12) b$ & $10.94(0.94) b$ & $4.43(0.31) b$ \\
\hline Nemaguard & $9.64(1.10) \mathrm{a}$ & $3.77(0.38)$ a & $17.11(1.37) \mathrm{a}$ & $6.39(0.51)$ a \\
\hline \multicolumn{5}{|c|}{ Winter pruning weight, January 1999} \\
\hline K-146-44 & $2.42(0.18) d$ & $1.29(0.18) \mathrm{d}$ & $3.95(0.32) \mathrm{d}$ & $2.11(0.11) \mathrm{d}$ \\
\hline K-146-43 & $3.56(0.16) \mathrm{cd}$ & $1.90(0.06) \mathrm{cd}$ & $5.28(0.41) \mathrm{d}$ & $2.83(0.06) \mathrm{d}$ \\
\hline Hiawatha & $5.58(0.51) \mathrm{c}$ & $2.98(0.24) \mathrm{c}$ & $7.76(0.83) \mathrm{cd}$ & $4.15(0.37) \mathrm{cd}$ \\
\hline P-30-135 & $8.23(0.59) b$ & $4.40(0.48) \mathrm{b}$ & $12.32(1.22) \mathrm{b}$ & $6.59(0.31) b$ \\
\hline K-119-50 & $9.77(0.45) \mathrm{b}$ & $5.22(0.19) \mathrm{b}$ & $11.21(0.99) \mathrm{bc}$ & $5.99(0.54) b c$ \\
\hline Nemaguard & 13.91 (1.14) a & $7.43(0.55) \mathrm{a}$ & $17.51(1.48) \mathrm{a}$ & $9.36(0.55) \mathrm{a}$ \\
\hline
\end{tabular}

${ }^{2}$ Different letters within columns indicate that means differ significantly (Tukey $P<0.05$ ). Numbers in parenthesis are sE. 
Table 5. Mean fresh crop weight and fruit load of third leaf 'Loadel' and 'Flavorcrest' open vase trees on six different rootstocks.

\begin{tabular}{|c|c|c|c|c|}
\hline \multirow[b]{2}{*}{ Rootstock } & \multicolumn{2}{|c|}{ Loadel } & \multicolumn{2}{|c|}{ Flavorcrest } \\
\hline & $\begin{array}{l}\text { Crop wtz } \\
\text { (kg/tree) }\end{array}$ & $\begin{array}{c}\text { Fruit no./ } \\
\text { tree }\end{array}$ & $\begin{array}{l}\text { Crop wtz } \\
\text { (kg/tree) }\end{array}$ & $\begin{array}{c}\text { Fruit no./ } \\
\text { tree }\end{array}$ \\
\hline K-146-44 & $32.7(1.87) \mathrm{d}$ & $301(19.1) \mathrm{c}$ & $17.0(1.79) \mathrm{c}$ & $138(14.8) \mathrm{c}$ \\
\hline K-146-43 & $35.0(1.98) \mathrm{d}$ & $299(18.3) \mathrm{c}$ & $19.0(1.39) \mathrm{c}$ & $142(98.3) \mathrm{c}$ \\
\hline Hiawatha & $48.5(3.49) \mathrm{c}$ & 379 (24.8) bc & $32.2(2.01) b$ & $225(12.4) b$ \\
\hline P-30-135 & $58.9(1.33) \mathrm{b}$ & 447 (16.9) ab & $33.0(23.3) b$ & $218(15.6) b$ \\
\hline K-119-50 & $66.3(3.06) \mathrm{ab}$ & $518(25.9) \mathrm{a}$ & $35.9(3.35) b$ & $223(23.8) b$ \\
\hline Nemaguard & $70.9(3.12) \mathrm{a}$ & 506 (22.8) a & $49.9(2.75) \mathrm{a}$ & $330(21.2) \mathrm{a}$ \\
\hline
\end{tabular}

z Different letters within columns indicate that means differ significantly (Tukey $P<0.05$ ).

Numbers in parenthesis are SE.

\section{Discussion}

Trunk Cross-Sectional area: ANNUAL InCREMENT AND SEASONAL GROWTH RATE. The results of this trial provide a good example of a wide range of vigor induced by peach rootstocks. It has been reported that rootstocks affect not only the absolute growth of the TCA but also the seasonal growth rate pattern of the scion trunk (Bernhard, 1985; Forshey and Elfving, 1989; Swarbrick, 1929; Tustin et al., 1997). Although TCA is not the only parameter used to describe the vegetative growth (Forshey and McKee, 1970; Preston, 1958; Wilcox, 1937a), it is indicative of cumulative growth from planting (Heinicke, 1922; Murray, 1927; Westwood and Roberts, 1970). Based on the initial trunk cross-sectional area (TCA), the six different rootstocks in both the 'Loadel' and the 'Flavorcrest' open vase trees could be grouped in three distinctive categories: $\mathrm{I}=$ semi-dwarf or dwarfing rootstocks (K-146-44 and K-146-43), II = intermediate rootstocks ('Hiawatha,' P-30-135 and K-119-50), and III = the most vigorous rootstock ('Nemaguard') which is the control (Table 1).

'Loadel' and 'Flavorcrest' open vase trees grafted on K-14644 and K-146-43 grew only $25 \%$ to $37 \%$ as much as trees on 'Nemaguard' (control). In apples, dwarfing rootstocks, such as M9 and M27 may produce a tree $15 \%$ to $35 \%$ the size of trees on seedling rootstocks (Rom and Carlson, 1987; Westwood, 1978) so K-146-44 and K-146-43 rootstocks appear to have effects on peach that are similar to M9 and M27 on apple.

The yearly TCA increment of both 'Loadel' and 'Flavorcrest' open vase trees followed a pattern similar to the initial TCA except that trees on P-30-135, with the 'Flavorcrest' scion, had a high growth rate that was comparable to trees on 'Nemaguard' (Table 1). During 1998, the seasonal TCA growth rate of 'Loadel' and 'Flavorcrest' open vase trees had different patterns depending on the rootstocks (Fig. 1). TCA of trees on the two most dwarfing rootstocks, K-146-44 and K-146-43, had almost continuous growth during the season, until October, but the TCA increase during August in the other rootstocks declined when the highest seasonal temperatures were recorded. The reduction in TCA growth in the largest rootstocks could have been a consequence of decreased water status after harvest caused by high temperatures, and relatively larger tree canopies, which would have the highest transpiration rate per tree. Canopy size induced by the more vigorous rootstocks also covered the assigned surface area more quickly than the smallest rootstocks. This could have reduced the available soil water content for the larger trees more than the smaller trees. Despite the reduction of August TCA growth in trees grafted on the invigorating rootstocks, the daily growth rate throughout the season was lower in trees on K-146-44 and $\mathrm{K}-146-43$ than in the other rootstocks.
Seasonal ShOOT GROWTH Rate. Several reports indicate that rootstocks markedly affect scion shoot growth and this parameter can be used as an indicator of vigor differences among rootstocks (Barlow, 1964; Forshey and Elfving, 1979; Khatamian and Hilton, 1977). The general growth pattern of shoots in each category (shoot type $\mathrm{B}, \mathrm{T}$ and $\mathrm{S}$ ) was similar among the different scion/rootstock combinations with an initial rapid growth and then a slowing growth rate after the middle of the summer. In general, shoots on 'Nemaguard' initially grew faster than on the other rootstocks, while shoots of the trees on K-146-44 and K-146-43 trees had the lowest growth rates (Fig. 2). More available carbohydrates may have been present in branches, scaffolds, trunk and roots of the large trees at the beginning of the season to allow the faster development of shoots and leaves on the more vigorous rootstocks compared to the dwarf rootstocks. However, no carbohydrates were analyzed in this study. No general differences were noted in the length of the growing season among the different rootstocks. Only 'Hiawatha' appeared to have an earlier slow-down of shoot growth which was accompanied with a decline of TCA increment and earlier leaf fall. Therefore, the observed differences in total shoot length between most rootstocks were attributable to rate of growth rather than length of the shoot growth period. The differences in internode length among the trees on various rootstocks were consistent with this hypothesis.

DIURNAL EXTENSION GROWTH RATE AFFECTED BY ROOTSTOCKS. Since shoot growth rate must be a function of diurnal shoot growth and Berman and DeJong (1997b) documented that diurnal shoot growth is a function of temperature and changes in stem water potential, we attempted to determine if differences in stem extension growth rate were related to diurnal patterns of stem water potential. The effect of changing water status on plant growth has been demonstrated by many studies (Acevedo et al., 1971; Hsiao and Jing, 1987). Water potential patterns and diurnal shoot growth in the current study were similar to those observed by Simonneau et al (1993) and Berman and DeJong (1997b), with stem dehydration occurring in the morning and rapid hydration occurring in the evening when the transpiration rate decreased. On 22 to 23 June 1999, trees on K-146-43 tended to have lower mean stem water potential and shoot extension growth rate than trees on 'Nemaguard', especially in the afternoon (Fig. 3). In general, trees grafted on dwarfing rootstocks had lower stem water potential, which may be related to low stem extension growth during the day. The observed reduction in diurnal stem extension growth rate in the dwarfing rootstocks may indicate the reason for the lower average shoot length of trees grafted on the more size-controlling rootstocks (Table 3 ). The higher stem water potential found on trees grafted on 'Nemaguard' compared to the more size-controlling ones, in particular K-146-43, could 
be the consequence of differences in hydraulic resistance at the bud union or in the root system (Olien and Lakso, 1984). Further studies related to this particular point could help in the understanding of a diurnal stem extension growth rate mechanism related to dwarfing rootstocks.

WINTER MEASUREMENTS: SHOOTS, LATERALS, WATERSPROUT, AND INTERNODE LENGTH. It has been reported that rootstocks directly affect the total growth of shoots (Murase et al., 1990; Salvatierra et al., 1998; Stutte et al., 1994; Wilcox, 1937b), and one of the most important parameters is the number and length of shoots and watersprouts because they are related to hand labor activities (pruning, thinning and harvest).

Although only trees on 'Nemaguard' differed significantly from trees on K-146-44 in the number of 1-year-old shoots per tree, there was a tendency for larger trees to have more shoots than smaller trees. The same trend was apparent in the estimated number of lateral shoots per tree, where trees on K-146-44 and K-146-43 had fewest, while trees on 'Nemaguard' and K-119-50 had the most (Table 2). Total shoot length and primary, secondary and tertiary growth per tree were significantly higher in trees grafted on 'Nemaguard' than on K-146-44 and K-146-43. Trees on K-119-50, 'Hiawatha' and P-30-135 had intermediate values (Table 2). Average shoot length also indicated a trend related to tree vigor, where trees on 'Nemaguard' had the longest shoots and trees on the dwarfing rootstocks, K-146-44 and K-146-43, had the shortest shoots.

Annual TCA increase was related with total shoot growth per tree.Apparently, the total increase in shoot length followed patterns similar to yearly TCA increment (Tables 1 and 2). These results are consistent with reports for apples (Heinicke, 1922; Khatamian and Hilton, 1977; Westwood and Roberts, 1970).

Before initiating the experiment, the presence of the largest shoots, watersprouts, was suspected to be associated with tree vigor. The shoot growth data made it clear that the largest trees, especially trees on 'Nemaguard', had the greatest watersprout growth per tree, including primary, secondary and tertiary growth (Fig. 4). These results suggest that $\approx 50 \%$ of the extension growth in the largest trees went into watersprouts, but much of this was removed by summer and dormant pruning (Table 4) representing an inefficiency in the peach production system.

Previous reports have found differences in the insertion angle of shoots induced by apple rootstocks (Crabbé, 1984; Preston, 1968; Warner, 1991). However, there were no significant differences or even trends supporting this concept in this peach experiment (data not shown).

Shoot internode length was associated with tree size. In general, the more size-controlling the rootstock, the shorter the internode length (Table 3). These results agree with Murasse et al. (1990) who reported that peach trees on less vigorous rootstocks produce shorter shoots with shorter internodes. In the present study, trees on more-size controlling rootstocks had shorter internode lengths than trees on the vigorous rootstocks, independent of the size of the shoots.

A noteworthy aspect of the individual shoot growth studies was that the variation in number of nodes of all $\mathrm{B}$ shoots arising from the basal nodes of the previous season lateral shoots (hangers) was very low $(9.8 \pm 0.2)$. There was slightly more variability in node number of $\mathrm{S}$ shoots (laterals shoots arising directly from scaffold wood) $(16.3 \pm 0.6)$ and $\mathrm{T}$ shoots arising from the terminal vegetative bud on hangers $(31.9 \pm 0.6)$. The consistent number of nodes of B shoots may reflect the number of preformed nodes inherent in lateral vegetative buds in this position on shoots of this cultivar ('Loadel'). If this is the case it would indicate that shoot growth in specific locations in peach trees is more determinate than commonly thought (Kramer and Kozlowski, 1979). The fact that the three different types of shoots had three different but relatively consistent node numbers per shoot may indicate that individual shoot node number is more dependent on point of morphological origin on the tree than the environmental condition/exposure during growth (Sabatier and Barthelemy, 2001).

INFLUENCE OF ROOTSTOCKS ON SUMMER AND WINTER PRUNING. Previous studies have indicated that pruning (summer and winter) is correlated with the size of the trees and particularly with rootstock vigor (Barlow, 1964, 1971; Forshey and McKee, 1970). Required summer and winter pruning was directly associated with the size of trees. It was necessary to remove more material from trees on 'Nemaguard', especially watersprouts. Dry weight removed from summer pruning of 'Loadel' and 'Flavorcrest' open vase trees on K-146-44 was $\approx 3 \%$ and $14 \%$, respectively, of trees on 'Nemaguard' (Table 4). Dormant pruning dry weight differences were similar. It is clear that dwarf peach rootstocks have advantages over more invigorating rootstocks relative to reduced summer and dormant pruning, and it is encouraging that major differences in vegetative growth between these rootstocks may be classified as excessive since much of it is growth that is removed during commercial pruning procedures.

INFLUENCE OF ROOTSTOCKS ON TREE YIELD. The fruit yield responses in this study are comparable to other research on peach rootstocks (Felipe et al., 1997; Minguzzi and Poli, 1988; Murase et al., 1990) where the general trend of the larger the tree the higher the yield per tree appears to fit. In California, 'Nemaguard' rootstock is known for producing trees with high vigor and high yields of large fruit. Clearly, the size-controlling rootstocks in this study produced trees with less vigor but unfortunately also less yield. However, since the trees in this study were only in their third year in the orchard it is too early to draw too many conclusions about the ultimate production efficiency of the various rootstocks. Longer-term yield data have been collected and reported elsewhere (DeJong et al., 2003).

The differences in tree yield and crop load between the 'Loadel' and 'Flavorcrest' scion cultivars on the various rootstocks may account for the tendency toward the apparent greater vigor of the 'Flavorcrest' trees compared to the 'Loadel' trees in some of the vegetative growth measurements. However, clearly most of the differences in vegetative growth among rootstocks with the same scion cultivar are due to rootstock differences and not crop load since crop load and yield were least on trees of the smaller rootstocks.

This experiment demonstrated significant effects of the tested rootstocks on vegetative growth of two peach cultivars. Annual TCA increment was related to the annual shoot growth in all the rootstocks. No marked differences were found in the general seasonal pattern of shoot growth among the studied rootstocks, but trees on the more vigorous rootstocks initially grew more rapidly than trees on the smallest rootstocks. Variations in shoot growth length were attributed to variations in the daily extension shoot growth, where the invigorating rootstocks induced the scion to grow faster than trees on the more size-controlling rootstocks. Correspondingly, average shoot and internode lengths were reduced in trees on the more size-controlling rootstocks. No differences were found in the insertion angle of shoots among trees on all the rootstocks. Total shoot growth per tree was proportional to the induced size, where watersprouts contributed 
to half of the growth with the vigorous rootstocks and only one-third to one-fourth of the growth on dwarfing rootstocks. However, shoot growth per unit of scaffold cross-sectional area was comparable among all but the smallest rootstocks. Summer and winter pruning was related to tree size so that trees grafted on the more size-controlling rootstocks, K-146-44 and K-146-43, required the least pruning.

\section{Literature Cited}

Acevedo, E, T.C. Hsiao, and D.W. Henderson. 1971. Immediate and subsequent growth responses of maize leaves to changes in water status. Plant Physiol. 48:631-636.

Barlow, H.W. 1964. An interim report on a long-term experiment to assess the effect of cropping on apple tree growth. Annu. Rpt. E. Malling Res. Sta. 1963:84-93.

Barlow, H.W. 1971. Plant physiology. Annu. Rpt. E. Malling Res. Sta. 1971:55-67.

Berman, M.E. and T.M. DeJong. 1996. Water stress and crop load effects on fruit fresh and dry weights in peach (Prunus persica). Tree Physiol. 16:859-864.

Berman, M.E. and T.M. DeJong. 1997a. Crop load and water stress effects on daily stem growth in peach (Prunus persica). Tree Physiol. $17: 467-472$.

Berman, M.E. and T.M. DeJong. 1997b. Diurnal patterns of stem extension growth in peach (Prunus persica): temperature and fluctuations in water status determine growth rate. Physiol. Plant. 100:361-370.

Bernhard, R. 1985. Rootstock influence on the growing rhythm and on the fertility of peach trees. Acta Hort. 173:191-197.

Chalmers, D.J. and I.B. Wilson. 1978. Productivity of peach trees: Tree growth and water stress in relation to fruit growth and assimilate demand. Ann. Bot. 42:294-295.

Childers, N.F. 1983. Modern fruit science: Orchard and small fruit cultures. 9th ed. Gainesville, Fla. Hort. Pub. p. 583.

Crabbé, J.J. 1984. Morphogenetical ways towards vigor restriction in spontaneous and man-made dwarf trees. Acta Hort. 146:113-117.

DeJong, T.M., J.F. Doyle, and K.R. Day. 1987. Seasonal patterns of reproductive and vegetative sink activity in early and late maturing peach (Prunus persica) cultivars. Physiol. Plant. 71:83-88.

DeJong, T.M., J.F. Doyle, R.S. Johnson, and D. Ramming. 1997. Evaluation of size controlling rootstocks for California peach production. Annu. Res. Rpt. Calif. Tree Fruit Agreement, Reedley, Calif.

DeJong, T.M., R.S. Johnson, J.F. Doyle, A. Weibel, L. Solari, B. Basile, J. Marsal, D. Ramming, and D. Bryla. 2003. Growth yield and physiological behavior of size-controling peach rootstocks developed in California. Acta Hort. (in press).

DeJong, T.M., W.Tsuji, J.F. Doyle, and Y.L. Grossman. 1999. Comparative economic efficiency of four peach production systems in California. HortScience 34:73-78.

Felipe, A., M. Carrera, and J. Gomez-Aparisi. 1997. 'Montizo' and 'Monpol', two new plum rootstocks for peaches. Acta Hort. 451:273-276.

Forshey, C.G. and D.C. Elfving. 1979. Estimating yield and fruit numbers of apple trees from branch samples. J. Amer. Soc. Hort. Sci. 104: 897-900.
Forshey, C.G. and D.C. Elfving. 1989. The relationship between vegetative growth and fruiting in apple trees. Hort. Rev. 11:229-287.

Forshey, C.G. and W. M. W. McKee. 1970. Production efficiency of a large and small "McIntosh" apple tree. HortScience 5:164-165.

Glenn, D.M. and R. Scorza. 1992. Reciprocal grafts of standard and dwarf peach alter dry-matter partitioning and root physiology. HortScience 27:241-243.

Heinicke, A.J. 1922. Some relationship between the circumference and weight, and between root top growth of young apple trees. Proc. Amer. Soc. Hort. Sci. 18:222-227.

Hsiao, T.C. and J. Jing. 1987. Leaf and root expansive growth in response to water deficits. Physiology of cell expansion during plant growth. Proc. Second Annu. Penn State Symp. Plant Physiol. 180-192.

Jones, O.P. 1984. Mode of action of rootstock/scion interactions in apple and cherry trees. Acta Hort. 146:175-182.

Kamboj, J.S., P.S. Blake, J.D. Quinlan, and A.D. Webster. 1997. Recent advances in studies on the dwarfing mechanism of apple rootstocks. Acta Hort. 451:75-82.

Khatamian, H. and R.J. Hilton. 1977. The relationship between shoot growth and area of trunk cross-section in several woody plant species. HortScience 12:255-257.

Kramer, P.J. and T.T. Kozlowski. 1979. Physiology of Woody Plants. Academic Press, New York.

Larson, K.D., T.M. DeJong, and R.S. Johnson. 1988. Physiological and growth responses of mature peach trees to postharvest water stress. J. Amer. Soc. Hort. Sci. 113:296-300.

Lockard, R.G., G.W. Schneider, and T.R. Kemp. 1982. Phenolic compounds in two size-controlling apple rootstocks. J. Amer. Soc. Hort. Sci. 107:183-186.

Maggs, D.H. 1957. A comparison for the growth patterns of two apple rootstock varieties during their first year. Annu. Rpt. E. Malling. Res. Sta. $101-105$

McCutchan H. and K.A. Shackel. 1992. Stem-water potential as a sensitive indicator of water stress in prune trees (Prunus domestica L. Cy French). J. Amer. Soc. Hort. Sci. 117:607-611.

McKenzie,D.W. 1961. Rootstock-scion interaction in apples, with special reference to root anatomy. J. Hort. Sci. 36:40-47.

Minguzzi, A. and M. Poli. 1988. Influenza del portinnesto nel reimpianto del pesco. L'Informatore Agrario 32:77-79.

Murase, S., T. Yamazaki, Y. Inomata, and K. Suzuki. 1990. Dwarfing rootstock for peach. Japan Agr. Res. Quart. 23:294-300.

Murray, C.D. 1927. A relationship between circumference and weight in trees and its bearing on branching angles. J. Gen. Physiol. 10: 725-729.

Olien, W.C. and A.N. Lakso. 1984. A comparison of the dwarf character and water relations of five apple rootstocks. Acta Hort. 146 151-158.

Preston,A.P. 1958. Apple rootstock studies. Thirty-five years' results with Lane's Prince Albert on clonal rootstock. J. Hort. Sci. 33:29-38.

Preston, A.P. 1968. Pruning and rootstock as factors in the production of primary branches on apple trees. J. Hort. Sci. 48:17-22.

Richards, D., W.K. Thompson, and R.P. Pharis. 1986. The influence of dwarfing interstocks on the distribution and metabolism of xylem-applied $\left[{ }^{3} \mathrm{H}\right]$ Giberellin A4 in apple. Plant Physiol. 82:1090-1095. 